Columbídeos, zoonoses e possíveis manejos para controle de população: um olhar geográfico

Columbidae, zoonoses and possible management for population control: a geographical view

Cárpidos, zoonosis y posibles manejos para control de población: una mirada geográfica

Marcelo Tenório Crepaldi Mestre, UEM, Brasil. tenriomarcelo@gmail.com

Mateus Fachin Pedroso Mestrando, UNESP - FCT, Brasil. mateus_fachin@hotmail.com

Maria Eugênia Moreira Costa Ferreira Professora Doutora, UEM, Brasil. eugeniaguart@hotmail.com 


\section{Periódica Eletrônica}

\section{Fórum Ambiental}

Volume 14, Número 2, 2018

da Alta Paulista

ISSN 1980-0827

\section{RESUMO}

A discussão apresentada tem como foco em primeira instância expor através de uma descrição taxonômica as características e hábitos de duas espécies (Columba livia; Zenaida auricula), bem como tratar da possível ocorrência de zoonoses, decorrente do contato entre seres humanos e as espécies supracitadas, tendo como objetivo, propor soluções de manejo para que haja o convívio harmônico entre sociedade e natureza. Para a viabilização do presente estudo foi realizado um levantamento de literatura acerca da taxonomia das espécies e suas características, tendo em vista as possíveis zoonoses transmitidas por esses animais, podendo então estabelecer um arcabouço científico substancial, apresentando por fim soluções e possíveis manejos levando em conta a convivência entre avifauna e ser humano no espaço geográfico. Tendo em vista as preocupações registradas e discutidas, acredita-se que a possibilidade de convívio harmônico entre seres humanos e aves é possível, desde que esta seja mediada por ações equilibradas que partem dos homens enquanto seres sociais, produtores do espaço geográfico, estando estas ações ao encargo dos órgãos públicos (Estado), bem como da população, referente à execução da educação ambiental.

PALAVRAS-CHAVE: Sociedade-natureza. Columbídeos. Manejo.

\section{ABSTRACT}

The present discussion focuses primarily on the characteristics and habits of two species (Columba livia; Zenaida auricula), as well as on the possible occurrence of zoonoses, due to the contact between humans and the species mentioned above, aiming at proposing management solutions so that there is harmony between society and nature. In order to make this study feasible, a literature survey was carried out on the taxonomy of the species and their characteristics, considering the possible zoonoses transmitted by these animals, and then establishing a substantial scientific framework, presenting finally solutions and possible management taking into account the coexistence between bird wild life and human being in the geographic space. In view of the concerns recorded and discussed, it is believed that the possibility of harmonious living between humans and birds is possible, provided that it is mediated by balanced actions that start from men as social beings, producers of the geographical space, these actions being to the charge of public agencies (State), as well as of the population, regarding the execution of environmental education.

KEY WORDS: Society-nature. Columbidae. Management.

\section{RESUMEN}

La discusión presentada tiene como foco en primera instancia exponer a través de una descripción taxonómica las características y hábitos de dos especies (Columba livia, Zenaida auricula), así como tratar de la posible ocurrencia de zoonosis, derivada del contacto entre seres humanos y las especies arriba citadas, con el objetivo, proponer soluciones de manejo para que haya la convivencia armónica entre sociedad y naturaleza. Para la viabilización del presente estudio se realizó un levantamiento de literatura acerca de la taxonomía de las especies y sus características, teniendo en cuenta las posibles zoonosis transmitidas por esos animales, pudiendo entonces establecer un marco científico sustancial, presentando por fin soluciones y posibles manejos teniendo en cuenta la convivencia entre avifauna y ser humano en el espacio geográfico. En cuanto a las preocupaciones registradas y discutidas, se cree que la posibilidad de convivencia armónica entre seres humanos y aves es posible, siempre que ésta sea mediada por acciones equilibradas que parten de los hombres como seres sociales, productores del espacio geográfico, estando estas acciones a la carga de los órganos públicos (Estado), así como de la población, referente a ejecución de la educación ambiental.

PALABRAS CLAVE: La sociedad y la naturaleza. Columbidae. Gestión. 


\section{Periódica Eletrônica}

\section{Fórum Ambiental}

\section{INTRODUÇÃO}

O estudo em questão, tem a preocupação com a problemática referente ao convívio entre pessoas e a população de columbídeos, principalmente em áreas urbanas. A discussão apresentada tem como foco em primeira instância expor através de uma descrição taxonômica as características e hábitos de duas espécies (Columba livia; Zenaida auriculata), bem como tratar da possível ocorrência de zoonoses, decorrente do contato entre seres humanos e as espécies supracitadas, tendo como objetivo, propor soluções de manejo para que haja o convívio harmônico entre sociedade e natureza.

São recorrentes casos de enfermidades associadas à transmissão, que envolvem columbídeos, em geral, as mesmas são de baixa prevalência no conjunto de outras doenças transmissíveis possuindo diagnósticos sub-clínicos. As doenças mais transmitidas por pombos são: criptococose, histoplasmose, ornitose, salmonelose e dermatites, tendo os columbídeos e seus excrementos como potenciais reservatórios no espaço (BRASIL, 2010).

O tema abordado carece de investigações que estejam preocupadas com a produção do espaço geográfico, permeado pela relação sociedade-natureza, que considera os elementos físicos, biológico e antrópicos, uma vez que tais interações sejam lidas e interpretadas a partir das alterações da paisagem (BERTRAND, 2004).

\section{OBJETIVO}

O cerne deste trabalho está pautado sob objetivo de apresentar possíveis soluções de manejos de espécies avícolas - em caráter preventivo - com enfoque na família Columbidae, especificadamente, as espécies Columba livia; Zenaida auricula, dado que estas espécies vivem e se reproduzem em grande quantidade na cidade, estabelecendo contato direto com os seres humanos, o que potencializa a probabilidade do surgimento de zoonoses.

\section{METODOLOGIA}

De acordo com D'Ancona (1966), quando se busca a classificação zoológica no campo da taxonomia, encontra-se inúmeras espécies da fauna com diversos graus de proximidade, decorrente disto, pode-se reuni-las conforme maior e menor grau semelhança. A partir dessa premissa, o autor relata o fato de os animais se distinguirem em um número de categorias sistemáticas para que possam ser identificados. Determinadas denominações são em ordem: reino, filo, classe, ordem, família, gênero e espécie. As espécies aqui estudadas diferem somente em gênero e espécie, dado que são da mesma família, a Columbidae, que compreendem os columbiformes. Gimenes et al., (2007) avaliam que pombas, juritis e rolinhas constituem a família Columbidae, a qual representa um grupo de aves que demonstra uma morfologia homogênea, com o corpo robusto, bico de tamanho pequeno e patas pequenas em relação ao corpo. Elas são predominantemente granívoras e/ou frutívoras e costumam fazer seus ninhos no solo ou em formações arbustivas.

Para a viabilização do presente estudo foi realizado um levantamento de literatura acerca da taxonomia das espécies e suas características, tendo em vista as possíveis zoonoses transmitidas por esses animais, podendo então estabelecer um arcabouço científico 


\section{Periódica Eletrônica}

\section{Fórum Ambiental}

Volume 14, Número 2, 2018

da Alta Paulista

ISSN 1980-0827

substancial, apresentando por fim soluções e possíveis manejos levando em conta a convivência entre avifauna e ser humano no espaço geográfico.

\section{MÉTODO DE ANÁLISE}

De acordo com os níveis hierárquicos acima citados, podemos então inserir as duas espécies aqui analisadas de acordo com seu grau de semelhança:

\begin{tabular}{|l|l|l|}
\hline \multicolumn{2}{|c|}{ Quadro 1 - Classificação Taxonômica de Columbídeos } \\
\hline Classificação & Columba lívia & Zenaída auriculata \\
\hline Reino & Animalia & Animalia \\
\hline Filo & Chordata & Chordata \\
\hline Classe & Aves & Aves \\
\hline Ordem & Columbiformes & Columbidarermes \\
\hline Família & Columbidae & Zenaida \\
\hline Gênero & Columba & Zenaida auriculata \\
\hline Espécie & Columba livia & \\
\hline
\end{tabular}

Fonte: Elaborado pelos autores, 2018.

\section{- Columba livia}

De acordo com Sick (2001), o pombo doméstico (Figura 1), foi introduzido no país no século $\mathrm{XVI}$, sendo este descendente do pombo bravo do Mediterrâneo. Atualmente, a ave assume o hábito de se nidificar em janelas de prédios e marquises em geral. Seus ninhos podem ser construídos com gravetos que variam de 5 a $20 \mathrm{~cm}$ de comprimento por 2 a $5 \mathrm{~mm}$ de diâmetro, dispostos muitas vezes lado a lado, que são fixados com as fezes das próprias aves (OGAWA 2008, p. 69-72).

Determinada espécie pode chegar a $38 \mathrm{~cm}$ de altura, apresenta as mais diversas plumagens e colorações. Sua reprodução não ocorre somente em estações mais favoráveis, como primavera e verão, podendo ser efetuadas várias posturas durante todo ano; nessas posturas são gerados dois ovos brancos chocados pelo casal durante um período de 17 dias (SICK, 2001). 


\section{Periódica Eletrônica}

\section{Fórum Ambiental}

Volume 14, Número 2, 2018

\section{da Alta Paulista}

ISSN 1980-0827

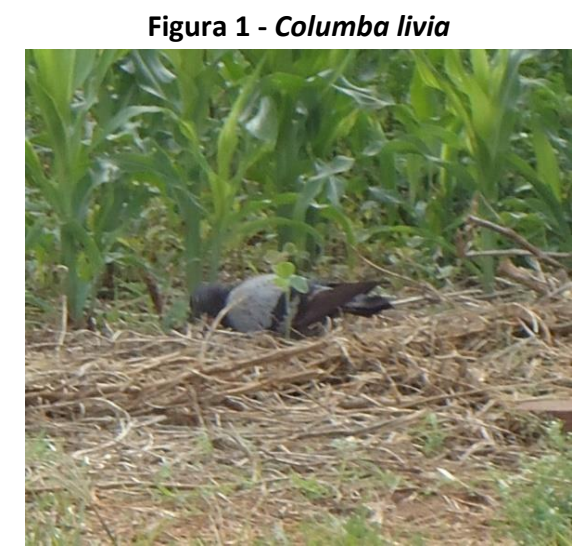

Fonte: Crepaldi, 2014.

Naturalmente, de caráter alimentar granívoro essa espécie conseguiu atingir um grau considerável de alterações em seus hábitos alimentares. Dentro desta perspectiva, vale ressaltar o sinantropismo desta espécie, visto que a adaptação ao meio urbano tem sido bemsucedida adquirindo assim hábitos alimentares detritívoros. Conforme Sigrist (2006), tal espécie é abundante em praças públicas, visto que consome restos de alimentos descartados de forma incorreta encontrados na superfície destas áreas.

Estes animais possuem uma reprodução relativamente rápida que está ligada parcialmente a oferta de alimento ao meio ao qual esta inserida. Estes fatores corroboram para a manutenção da existência e permanência de superpopulações destes espécimes. Dada esta análise é possível identificar uma concentração dessa população nos grandes centros, principalmente nas regiões do Centro-Oeste, Sudeste e Sul do Brasil (Figura 2). Em locais onde há fartura de alimento, acontece uma maior reprodução e, consequentemente, uma maior população dessas aves.

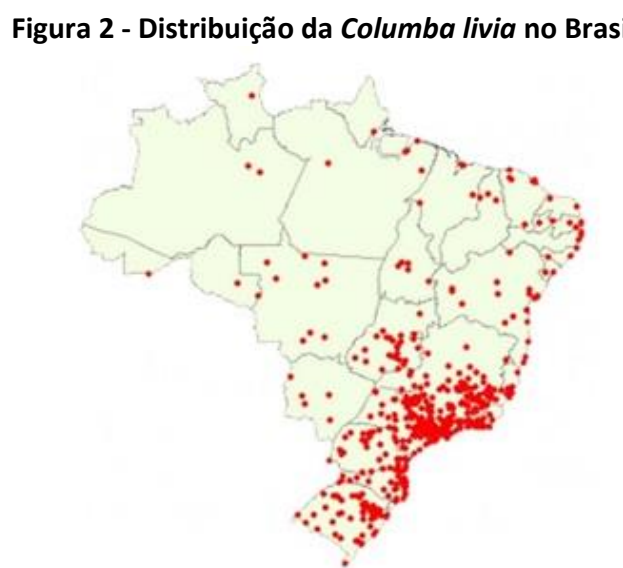

Fonte: Wiki Aves, 2018.

\section{- Zenaida auriculata}

Os estudos de Antas (1986) distribuem a Zenaida auriculata, ou pomba-de-bando, pombaamargosa ou avoante (Figura 3) pelas formações abertas da Américas do Sul, desde a Colômbia, Venezuela, Trinidad-Tobago e Guianas até o centro sul da Argentina. 


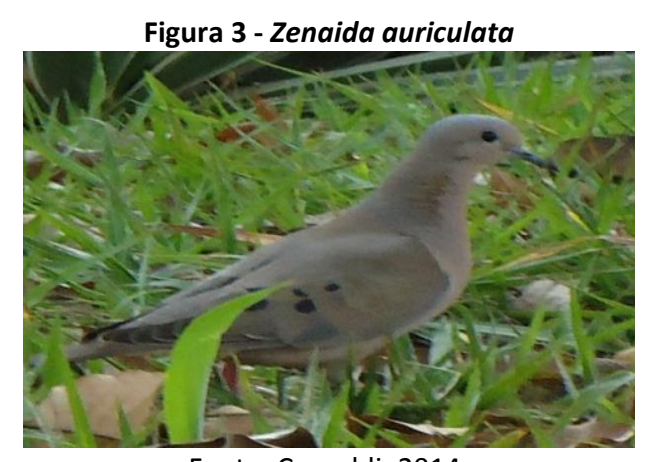

Fonte: Crepaldi; 2014.

São aves de ocorrência muito comum em áreas de cultivo de grãos. Esse fato é considerado uma problemática para a agricultura, especialmente no que se relaciona ao cultivo de soja. 0 monocultivo atrai esta espécie enquanto consumidores de grande eficiência, fazendo deste encontro uma grave problemática, já que há um desequilíbrio entre as espécies e seus predadores naturais.

Gimenes et al.., (2007) informa que a pomba-de-bando habita regiões abertas, áreas de pastagem e plantações. Além disso, ela é comumente registrada em áreas que sofreram antropização, assim como áreas de vegetação aberta como campos e zonas arbustivas.

Gimenes destaca ainda que a espécie $Z$. auriculata, tem o hábito de fazer seus ninhos no chão, em árvores ou em formações arbustivas. Posterior ao acasalamento, há a postura de 1 ou 2 ovos de coloração branca. Os filhotes são alimentados pelos pais através de "leite de papo", que consiste em alimento regurgitado. Sua alimentação é composta basicamente de grãos, sementes, pequenos insetos e pequenos frutos apanhados no solo.

Sick (2001) pondera que há possibilidade que tal espécie avícola modifique seus hábitos, adaptando-se às alterações do ambiente, e vem apresentando hábitos de postura nos solos dos Estados de São Paulo e Paraná, particularmente nos canaviais (extensas áreas de monocultura de cana-de-açúcar).

A partir de estudos de Murton et al.., (1974), a espécie Zenaida auriculata, quando em condições favoráveis, está presente nas caatingas, campos limpos e cerrados. Supõe-se que essa espécie tenha migrado pelo país através da busca de alimentos e alocação a partir de sua ecologia.

Com relação à migração da pomba de bando do Nordeste brasileiro para o Sul do país, nota-se que a ocorrência se deu a partir de 1970 no interior dos estados do Paraná e de São Paulo, quando as aves se adaptaram ao ambiente criado pelo crescimento da agricultura e da pecuária (WIKIAVES, 2018).

A ave em questão pode ter uma característica migratória diferente daquela que vem somente do Nordeste brasileiro. Determinada espécie é muito comum na Patagônia e nos campos argentinos, podendo também migrar dessa região atraída também pela oferta de alimento, com o advento da agricultura.

Segundo Ranvaud (2001), agricultores do médio Vale do Paranapanema, tem relatado problemas com a espécie Zenaida auriculata, que se alimentam da soja na época do plantio. 0 autor ressalta também que as aves se refugiam em áreas de cultura de cana, estabelecendo ali colônias, denotando então grande adaptação a paisagens criadas por práticas agrícolas e 
também aos alimentos que as mesmas ofertam. Em contrapartida, quando algum refúgio se encontra em falta, elas se deslocam para áreas urbanas a fim de se proteger.

Quanto a sua distribuição no país (Figura 4) verifica-se um grande acúmulo nas regiões CentroOeste, Sudeste e Sul.

Figura 4 - Distribuição da Zenaida auriculata no Brasil.

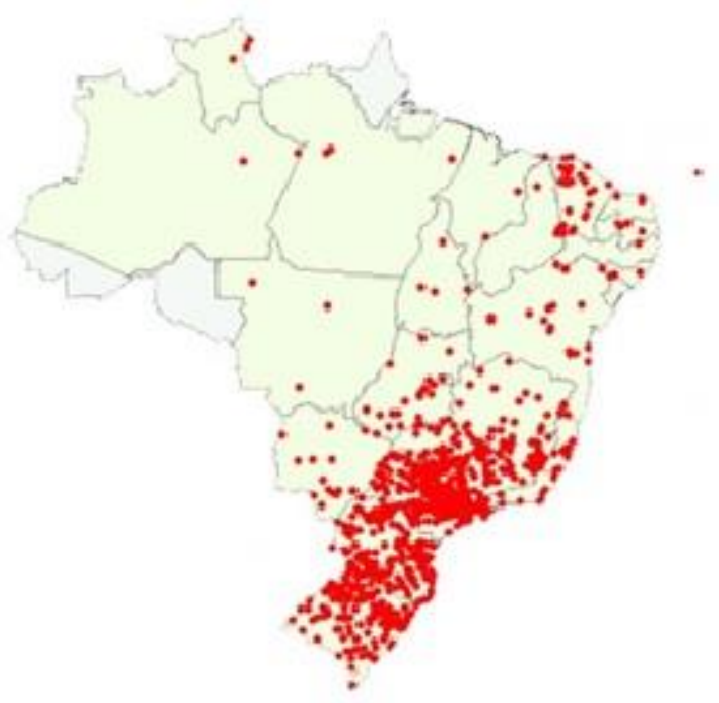

Fonte: Wiki Aves, 2018. 


\section{RESULTADOS}

\section{MANEJO DE COLUMBÍDEOS}

Para o controle e manejo dessas aves, são necessárias práticas e medidas de prevenções a serem adotadas. Vale ressaltar também que o manejo a ser realizado deve considerar o não sofrimento ou a morte da espécie, atendendo à legislação ambiental entre outras. Em relação ao pombo europeu, por ser detritívoro e urbano, seria necessário na prática tornar as cidades mais limpas, livres de detritos nas ruas, praças e, particularmente, nas zonas comerciais. Tais medidas exigiriam a colocação de lixeiras com tampa, a reeducação ambiental da população para o não descarte dos detritos em vias públicas.

Com relação às práticas complementares, junto à população humana pode-se estimular o seguinte:

- Conscientização para a diminuição gradual da alimentação por parte da população das aves, para que os animais possam buscar na natureza seu alimento, diminuindo assim sua reprodução e migrando para outras regiões;

- Controlar o abrigo das aves nas residências, que se a partir da instalação de telas nos forros e telhados de casas, prédios e marquises impedindo assim a alocação dessas aves nesses espaços:

- Utilização de materiais pontiagudos, com o intuito de evitar que os pombos pousem e faça ninhos;

- Aplicação de materiais pegajosos, de forte odor (por exemplo a creolina) e brilhantes (que simulem um predador e exerçam a função de um espantalho), para que os animais evitem determinados lugares.

- Conforme Nunes (2003), categoriza o manejo de diferentes formas, sendo elas:

- De baixo impacto: inclinação da superfície de pouso; uso de estruturas que impeçam ou desestabilizem o pouso; emprego de espantalhos; emprego de refletores luminosos; emprego de aves de rapina; equipamentos sonoros de ultrassom; tiros de ar comprimido.

- De baixo impacto e risco a outrem: sonorizadores diversos; fogos de artifício; gel irritantes de contato; cercas eletrificadas; armadilhas para captura; uso de anticoncepcional (quimoesterelizante a base de hidro cloro).

- Medidas proibidas: uso de arma de fogo; envenenamento; captura e soltura em área aleatória.

- Medidas duráveis: vedação de espaços e vãos; uso de abrigos controlados.

- Medidas complementares: destinação de resíduos em geral; controle de fontes alternativas de fornecimento.

- Voluntário de alimento: controle de ectoparasitos; limpeza e desinfecção dos locais de abrigo; educação, orientação e esclarecimento da população.

Quanto à pomba de bando, é de extrema importância compreender sua característica ecológica. Essa espécie alimenta-se principalmente no meio rural, onde encontra áreas de cultivos extensivos, em vista do desequilíbrio causado pelo monocultivo e pelo desmatamento. 
Não parece haver interesse por parte de órgãos públicos, no entanto, em restabelecer um reequilíbrio ecológico por meio da adequação do sistema de cultivo a um modelo policultor, bem como de restabelecer uma melhor relação entre as áreas de cultivo e as áreas florestadas. Como a espécie é nativa do Brasil, ela é protegida por lei relacionadas ao seu abate.

O IBAMA (Instituto Brasileiro do Meio Ambiente e dos Recursos Naturais Renováveis) decretou uma Instrução Normativa de n¹08/2006 a qual determinou por um período, as condições para se proceder ao abate das pombas Zenaida auriculata:

\footnotetext{
O Presidente do Instituto Brasileiro do Meio Ambiente e dos Recursos Naturais Renováveis - IBAMA, nos usos das atribuições que lhe confere o art. 26 incisos V e VIII do Anexo I, da Estrutura Regimental aprovada pelo Decreto no 5.718, de 13 de março de 2006, e o artigo 95, inciso VI do Regimento Interno aprovado pela Portaria GM/MMA n-230, de 14 de maio de 2002;

Considerando que a Lei ํo 5.197, de 03 de janeiro de 1967, em seu artigo 3요 § 2 응 permite a destruição de animais silvestres considerados risco a saúde pública;

Considerando a necessidade de efetuar o controle populacional da pomba-amargosa - Zenaida auriculata - nos municípios onde é considerada nociva à agricultura, pelos danos causados às culturas de grãos e frutos... (IBAMA - Instrução Normativa no 108, de 1 de Agosto de 2006, p. 72, Diário Oficial da União - Seção 1)
}

Determinado controle populacional pelo período de um ano, compreendendo o correto abate dessas populações, os requisitos que o agricultor precisaria apresentar para executá-las e as punições cabíveis, caso fosse descumprida.

Um fator a se destacar com questão a este manejo proposto pelo IBAMA é quanto a sua correta exequibilidade. Como o manejo proposto decorre de várias normas e condutas para correta aplicação, fica inviável para os agricultores adotarem essa norma vigente, sendo que a maioria não pratica o correto manejo da população devido às normas apresentadas. Os agricultores, visando não perder sua produção, podem adotar medidas impróprias e/ou ilegais para lidar com o caso. Eles acabam por não adotar medidas ecológicas, sendo a principal delas o restabelecimento de áreas florestadas e a introdução de um policultivo. 


\section{CONSIDERAÇÕES FINAIS}

Tendo em vista as preocupações registradas e discutidas, acredita-se que a possibilidade de convívio harmônico entre seres humanos e aves é possível, desde que esta seja mediada por ações equilibradas que partem dos homens enquanto seres sociais, produtores do espaço geográfico, estando estas ações ao encargo dos órgãos públicos (Estado), bem como da população, referente à execução da educação ambiental.

Portanto, é necessário encontrar uma forma ajustada de manejo, ou seja, que não haja sofrimento para os animais, visto que eles fazem parte da fauna urbana, bem como, reeducar a população, para entender que eles fazem parte do nosso ambiente, e que estes fatos representam os principais pontos de convergência para o equilíbrio da convivência entre o ser humano e os columbídeos, como parte integrante do ecossistema e não como fauna indesejável que deva ser eliminada.

\section{REFERÊNCIAS BIBLIOGRÁFICAS}

ANTAS, P. T. Z; A nidificação da avoante, Zenaida auriculata, no Nordeste do Brasil, relacionada com o substrato fornecido pela vegetação. Revista Brasileira de Zoologia, vol. 3, n.7, p. 467-470, 1986.

BERTRAND, G. Paisagem e Geografia Física global: esboço metodológico. RAE GA, Curitiba, n. 8, p. 141-152, 2004.

BRASIL. Doenças infecciosas e parasitárias: guia de bolso. Ministério da Saúde, Secretaria de Vigilância em Saúde, Departamento de Vigilância Epidemiológica. - 8. ed. rev. Brasília: Ministério da Saúde, 2010.

CREPALDI, M. T. Geografia e saúde: a zoogeografia dos columbídeos em Maringá - PR. 2014. Dissertação (Mestrado em Geografia) - Universidade Estadual de Maringá - UEM.

D'ANCONA, H. Trattado di Zoologia. - 2.Ed. - Barcelona: Editora Labor, S. A, 1966.

GIMENES, M. R; et al; Aves da planície alagável do alto Paraná. 22.ed. Eduem. Maringá PR, 2007.

IBAMA, Instituto Brasileiro do Meio Ambiente e dos Recursos Naturais Renováveis. Instrução Normativa no 108, de 1 de Agosto de 2006, p. 72, Diário Oficial da União - Seção 1.

MURTON, R. K; et al. The ecology of the eared dove Zenaida Auriculata in Argentina. 1974.

NUNES, V. F. P; Pombos Urbanos o desafio do Controle. Biológico, São Paulo, v.65, n.1, p.89-92, 2003.

OGAWA, G. M; Artrópodes em Ninhos de Columba livia Gmelin, 1789 (Aves, Columbidae) em Área Urbana de Manaus, Amazonas, Brasil. EntomoBrasilis, v. 1, n. 3, p. 69-72, 2008.

RANVAUD, R. et al. Diet of Eared Doves (Zenaida auriculata, Aves, Columbidae) in a sugar-cane colony in Southeastern Brazil. Brazilian Journal of Biology, São Carlos, v. 61, n. 4, nov. 2001.

SICK, H. Ornitologia brasileira. Rio de Janeiro: Ed. Nova Fronteira, 2001.

SIGRIST, T. Aves do Brasil: uma visão artística. São Paulo: Tomas Sigrist. 2006.

WIKIAVES - Enciclopédia de Aves Brasileira. Disponível em: <http://wikiaves.com.br/pomba-de-bando>. Acessado em 21/05/2018. 